This document is the accepted manuscript version of the following article:

Hugonnet, R., McNabb, R., Berthier, E., Menounos, B., Nuth, C., Girod, L., ... Kääb, A. (2021). Accelerated global glacier mass loss in the early twenty-first century. Nature, 592, 726-731. https://doi.org/10.1038/s41586-021-03436-z

\title{
Accelerated global glacier mass loss in the early twenty-first century
}

\author{
Romain Hugonnet ${ }^{1,2,3^{*}}$, Robert McNabb ${ }^{4,5}$, Etienne Berthier ${ }^{1}$, Brian Menounos ${ }^{6,7}$, Christopher \\ Nuth $^{5,8,9}$, Luc Girod ${ }^{5}$, Daniel Farinotti ${ }^{2,3}$, Matthias Huss ${ }^{2,3,10}$, Ines Dussaillant ${ }^{1,11}$, Fanny Brun ${ }^{12}$ \\ and Andreas Kääb ${ }^{5}$
}

\author{
${ }^{1}$ LEGOS, Université de Toulouse, CNES, CNRS, IRD, UPS, Toulouse, France. \\ ${ }^{2}$ Laboratory of Hydraulics, Hydrology and Glaciology (VAW), ETH Zürich, Zürich, Switzerland. \\ ${ }^{3}$ Swiss Federal Institute for Forest, Snow and Landscape Research (WSL), Birmensdorf, Switzerland. \\ ${ }^{4}$ School of Geography and Environmental Sciences, Ulster University, Coleraine, United Kingdom. \\ ${ }^{5}$ Department of Geosciences, University of Oslo, Oslo, Norway. \\ ${ }^{6}$ Natural Resources and Environmental Studies Institute and Geography, University of Northern British \\ Columbia, Prince George, British Columbia, Canada. \\ ${ }^{7}$ Hakai Institute, Quadra Island, Canada. \\ ${ }^{8}$ The Norwegian Defense Research Establishment, Kjeller, Norway. \\ ${ }^{9}$ Heimdal Satellite Technologies, Oslo, Norway. \\ ${ }^{10}$ Department of Geosciences, University of Fribourg, Fribourg, Switzerland. \\ ${ }^{11}$ Department of Geography, University of Zurich, Zurich, Switzerland. \\ ${ }^{12}$ IGE, Université Grenoble Alpes, CNRS, IRD, Grenoble INP, Grenoble, France.
}

*e-mail: romain.hugonnet@gmail.com

Glaciers distinct from the Greenland and Antarctic ice sheets are shrinking rapidly, altering regional hydrology ${ }^{1}$, raising global sea-level ${ }^{2}$ and elevating natural hazards ${ }^{3}$. Yet, due to the scarcity of constrained mass loss observations, glacier evolution during the satellite era is only known as a geographic and temporal patchwork ${ }^{4,5}$. Here we reveal the accelerated, albeit contrasted, patterns of glacier mass loss during the early twenty-first century. By leveraging largely untapped satellite archives, we chart surface elevation changes at a high spatiotemporal resolution over all of Earth's glaciers. We extensively validate our estimates against independent, high-precision measurements and present the first globally complete and consistent estimate of glacier mass change. We show that, during 2000-2019, glaciers lost $267 \pm 16 \mathrm{Gt}_{\mathrm{yr}^{-1}}$, equivalent to $21 \pm 3 \%$ of

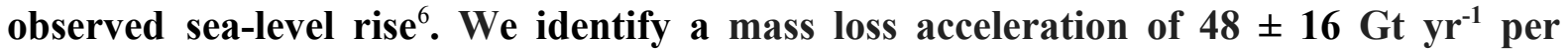
decade, explaining 6-19\% of the observed acceleration of sea-level rise. Particularly, thinning rates of glaciers outside ice sheet peripheries doubled over the last two decades. Glaciers presently lose more mass, and at similar or larger accelerated rates, than the Greenland or Antarctic ice sheets taken separately ${ }^{7-9}$. Uncovering the patterns of mass change in many regions, we find contrasted glacier fluctuations that agree with decadal variability in precipitation and temperature. Those include a newly-identified North Atlantic anomaly of decelerated mass loss, a strongly accelerated loss from Northwestern American glaciers and the apparent end of the Karakoram anomaly of mass gain ${ }^{10}$. We anticipate our highly-resolved estimates to foster the understanding of drivers that govern the distribution of glacier change, and to extend our capabilities of predicting these changes at all scales. Predictions robustly benchmarked against 


\section{observations are critically needed to design adaptive policies for the management of local water resources and cryospheric risks as well as for regional-to-global sea-level rise.}

About 200 million people live on land predicted to fall below the high-tide lines of rising sea levels by the end of the century ${ }^{11}$, while more than one billion could face water shortage and food insecurity within the next three decades ${ }^{4}$. Glaciers distinct from the ice sheets play a prominent role in these repercussions as the largest estimated contributor to twenty-first century sea-level rise after thermal expansion ${ }^{2}$, and as one of the most climate-sensitive constituents of the world's natural water towers ${ }^{12,13}$. Current glacier retreat temporarily mitigates water stress on populations reliant on ice reserves by increasing river runoff ${ }^{1}$, but this short-lived effect will eventually decline ${ }^{14}$. Understanding present-day and future glacier mass change is thus crucial to avoid water scarcity-induced socio-political instability ${ }^{15}$, to predict the alteration of coastal areas due to sea-level rise ${ }^{4}$, and to assess the impacts on ecosystems ${ }^{16}$ as well as on cryosphere-related hazards ${ }^{3}$.

Despite this, glacier mass change stands out as one of the least-constrained elements of the global water cycle, identified as a critical research gap by the Special Report on the Ocean and Cryosphere in a Changing Climate (SROCC) of the Intergovernmental Panel on Climate Change (IPCC) ${ }^{4}$. Observational limits stem from the fragmented expanse of glacierized surfaces around the globe. Largely inaccessible, only a few hundred out of the more than 200,000 glaciers are monitored in-situ ${ }^{17}$. Notwithstanding recent progress in glacier monitoring from space ${ }^{18}$, global-scale remote sensing-based studies have been so far limited to (i) the coarse spatial resolution of satellite gravimetry, unable to reliably disentangle glacier mass change signals from those of the ice sheets, solid Earth and hydrology in many regions ${ }^{5,19,20}$; (ii) the sparse repeat sampling of satellite altimetry that operated over short timespans $^{5,10}$ and; (iii) the uneven coverage of optical and radar surface elevation change estimations that account at most for $10 \%$ of the world's glaciers ${ }^{21}$.

\section{Spatiotemporally resolved estimation}

In this study, we leverage large-scale and openly available satellite and airborne elevation datasets as a means of either estimation, reference, or validation of Earth's surface elevation over all glaciers and their vicinity between January 1, 2000 and December 31, 2019 (Extended Data Fig. 1). For observational coverage, we rely mostly on NASA's 20-year long archive of stereo-images from the Advanced Spaceborne Thermal Emission and Reflection Radiometer (ASTER). We use modern photogrammetry techniques and specifically-developed statistical methods to generate and bias-correct nearly half a million Digital Elevation Models (DEMs) at $30 \mathrm{~m}$ horizontal resolution. In total, our repeat DEMs cover more than 20 times the land area on Earth (Extended Data Fig. 2).

Changes in glacier elevation based on DEMs are traditionally quantified by differencing pairs of acquisitions from two distinct epochs. To harness the full potential of the repeat temporal coverage provided by the archives, we introduce an approach to produce continuous elevation time series interpolated from all available DEMs (see Methods, Extended Data Fig. 3). This technique allows us to mitigate the strong effects of seasonality while preserving longer, 
non-linear glacier elevation changes through time. In total, we independently compute surface elevation time series for about half a billion pixels at a horizontal resolution of $100 \mathrm{~m}$, covering $97.4 \%$ of inventoried glacier areas ${ }^{22}$ with an average of 39 independent observations per pixel between 2000 and 2019 (Extended Data Table 2). Using glacier-wide hypsometric gap-filling methods, we then extend our estimated elevation changes to nearly $99.9 \%$ of glacier areas.

We perform an extensive validation by intersecting our elevation time series with 25 million high-precision measurements from NASA's Ice, Cloud, and land Elevation Satellite (ICESat) and Operation IceBridge campaigns over glaciers, spanning 2003 to 2019. We thereby confirm the absence of temporal and spatial biases in our elevation change estimates (see Methods, Extended Data Fig. 4). We further utilize ICESat data to constrain the spatiotemporal correlations that are either structural to our interpolated elevation time series or that emerge due to latent, uncorrected ASTER instrument noise, and we propagate our elevation errors into volume change errors accordingly. We validate the reliability of our uncertainty estimates down to the scale of individual glaciers by comparison to independent, high-precision DEM differences for 588 glaciers around the globe (Extended Data Fig. 5).

Integration of elevation changes over each of the 217,175 inventoried glaciers yields volume change, subsequently converted to water-equivalent mass change ${ }^{23}$. Our analysis includes $200,000 \mathrm{~km}^{2}$ of glaciers located in the Greenland Periphery and in the Antarctic and Subantarctic, referred to as peripheral glaciers, that are distinct from the Greenland Ice Sheet (GIS) and the Antarctic Ice Sheet (AIS). We aggregate our estimates over the 19 first-order regions of the Randolph Glacier Inventory 6.0 (RGI 6.0) ${ }^{22}$ (Fig. 1), and report estimates for periods exceeding five years due to larger uncertainties at shorter time scales (Extended Data Table 1). Uncertainties, provided at the 95\% confidence level (two standard deviations), depend primarily on observational coverage. When converting from volume to mass change, our estimates are largely hampered by a poor knowledge of density conversion ${ }^{23}$ which constitutes the dominant uncertainty component of our glacier mass change assessment.

\section{Global contribution to sea-level rise}

From 2000 to 2019, global glacier mass loss totalled $266 \pm 16 \mathrm{Gt} \mathrm{yr}^{-1}$, a mass loss $47 \%$ larger than that of the GIS, and more than twice that of the $\operatorname{AIS}^{7-9}$ (Table 1). Assuming all meltwater ultimately reached the ocean, the contribution to sea-level rise was $0.74 \pm 0.04 \mathrm{~mm} \mathrm{yr}^{-1}$ or 21 $\pm 3 \%$ of the observed rise ${ }^{24}$. Global glacier mass loss rapidly accelerated (see Methods) at a rate of $48 \pm 16 \mathrm{Gt} \mathrm{yr}^{-1}$ per decade (62 $\pm 8 \mathrm{Gt} \mathrm{yr}^{-1}$ per decade excluding peripheral glaciers), corresponding to a thinning rate acceleration of $0.10 \pm 0.02 \mathrm{~m} \mathrm{yr}^{-1}$ per decade $(0.16 \pm 0.02 \mathrm{~m}$ $\mathrm{yr}^{-1}$ per decade). While thinning rates increased steadily, mass loss acceleration slightly attenuated in time due to the decreasing extent of glacier surfaces caused by glacier retreat. Excluding peripheral glaciers, thinning rates nearly doubled from $0.36 \pm 0.21 \mathrm{~m} \mathrm{yr}^{-1}$ in 2000 to $0.69 \pm 0.15 \mathrm{~m} \mathrm{yr}^{-1}$ in 2019 . Observational studies were yet unable to discern significant accelerated glacier mass loss ${ }^{19,21}$, with the exception of a recent gravimetric study ${ }^{20}$ that estimated an acceleration of $50 \pm 40 \mathrm{Gt} \mathrm{yr}^{-1}$ per decade excluding peripheral glaciers. Despite its large uncertainties, the latter estimate is in agreement with our results. The observed acceleration of mass loss for glaciers exceeds that of the GIS $^{7}$ and is similar to that of the 
AIS $^{8}$. For the AIS, gravimetric observations indicate a decelerating mass loss since the mid- $2010 \mathrm{~s}^{25}$. We thereby infer that acceleration of sea-level rise since 2000, often attributed to the accelerated loss from both the GIS and AIS, also substantially originates from glaciers. Observed sea-level trends ${ }^{24}$ place the glacier contribution at $6-19 \%$ of the acceleration in global sea-level rise, with a mean estimate at $9 \%$. The large spread of this contribution primarily arises from uncertainties in the observed acceleration of sea-level rise ${ }^{24}$.

Marine-terminating glaciers collectively represent $40 \%$ of Earth's total glacierized area, yet only contribute $26 \%$ to the global mass loss (Fig. 1). This smaller contribution to sea-level rise is uniform for all maritime regions, except where losses of marine-terminating glaciers are dominated by recent large surge events (e.g. Svalbard and Jan Mayen, Extended Data Fig. 6). The delayed and asynchronous response of tidewater glaciers to changes in climate ${ }^{26}$ may partly explain why most marine-terminating glaciers show reduced mass loss. Despite differing mass loss rates, relative acceleration of land- and marine-terminating glaciers within each maritime region are similar (Extended Data Table 3). Notable exceptions exist for glaciers in the Antarctic and Subantarctic, where few land-terminating glaciers are present, and in regions of strong surge-driven mass losses.

\section{Regionally-contrasted mass changes}

Seven glacierized regions account for $83 \%$ of the global mass loss (Extended Data Table 1): Alaska (25\%); the Greenland Periphery (13\%); Arctic Canada North and South (10\% each); Antarctic and Subantarctic, High Mountain Asia - composed of Central Asia, South Asia West and South Asia East - and the Southern Andes (8\% each). From 2000 to 2019, specific mass change (i.e. mass change divided by area) strongly varied in latitudinal belts (Fig. 2). The large, northernmost Arctic regions composed of northern Arctic Canada and Greenland Periphery, Svalbard and Jan Mayen, and the Russian Arctic, all showed moderate specific mass change rates, averaging $-0.28 \pm 0.04 \mathrm{~m}$ w.e. $\mathrm{yr}^{-1}$. Further South in the Arctic - at latitudes encompassing Alaska, Arctic Canada South, southern Greenland Periphery, Iceland, and Scandinavia - specific mass change rates were consistently more negative, at a near-triple $-0.74 \pm 0.10 \mathrm{~m}$ w.e. $\mathrm{yr}^{-1}$, reaching the world's most negative regional rate over the two decades of $-0.88 \pm 0.13 \mathrm{~m}$ w.e. $\mathrm{yr}^{-1}$ in Iceland. Non-polar regions also experienced substantial mass loss $\left(-0.69 \pm 0.11 \mathrm{~m}\right.$ w.e. $\mathrm{yr}^{-1}$ on average $)$ with the exception of High Mountain Asia (-0.22 \pm 0.05 m w.e. $\left.\mathrm{yr}^{-1}\right)$. The Antarctic and Subantarctic exhibited the least negative specific mass change rate of $-0.17 \pm 0.04 \mathrm{~m}$ w.e. $\mathrm{yr}^{-1}$.

Our regional mass change estimates closely match those of a recent gravimetric study ${ }^{19}$ in remote polar regions (Arctic Canada, Svalbard and Jan Mayen, and the Russian Arctic) where gravimetric uncertainties are considered small due to weak competing signals ${ }^{27}$ (Fig. 3). We note, however, large discrepancies between the latter gravimetric study ${ }^{19}$ and a more recent one $^{20}$ in both Iceland and the Russian Arctic. We find good agreement with the dense in-situ measurements of Central Europe, Scandinavia or New Zealand ${ }^{5}$. In High Mountain Asia and the Southern Andes, where gravimetric and glaciological records are less constrained, our mass change estimates of $-0.21 \pm 0.05$ and $-0.67 \pm 0.15 \mathrm{~m}$ w.e. $\mathrm{yr}^{-1}$, respectively, are slightly more negative than the $-0.19 \pm 0.06$ and $-0.64 \pm 0.04 \mathrm{~m}$ w.e. $\mathrm{yr}^{-1}$ reported from recent DEM-based studies ${ }^{28,29}$. In the Low Latitudes, our estimate of $-0.43 \pm 0.12 \mathrm{~m}^{\text {w.e. }} \mathrm{yr}^{-1}$ is about 
twice as negative as that of a recent interferometric radar study ${ }^{29}$ of $-0.23 \pm 0.08 \mathrm{~m}$ w.e. $\mathrm{yr}^{-1}$, a difference that plausibly originates from biases associated with the penetration of radar signals into ice and firn ${ }^{30}$.

\section{Drivers of temporal variabilities}

While global glacier mass loss distinctly accelerated, the loss from glaciers peripheral to the GIS and AIS slightly decelerated, from $65 \pm 16 \mathrm{Gt} \mathrm{yr}^{-1}$ in 2000-2004 to $43 \pm 13 \mathrm{Gt} \mathrm{yr}^{-1}$ in 2015-2019 (Extended Data Table 1). Variability within the ice sheet peripheries was strong, however (Fig. 2, Fig. 4a). The peculiar surface elevation change patterns we capture for glaciers fringing Greenland, particularly notable around the eastern Greenland subregions of mass gain in 2015-2019 (Extended Data Fig. 7), mirror those observed by satellite radar altimetry for the outer parts of the GIS ${ }^{31}$. Similarly, the elevation change rate patterns of Antarctica's scattered peripheral glaciers largely agree with mass changes reported for the AIS $^{8}$. Western Antarctic peripheral glaciers substantially lost mass $\left(-0.23 \pm 0.06 \mathrm{~m} \mathrm{yr}^{-1}\right)$ while those of East Antarctica slowly thickened $\left(0.04 \pm 0.05 \mathrm{~m} \mathrm{yr}^{-1}\right)$. Ice masses surrounding the Antarctic Peninsula, representing 63\% of the glacier area in the Antarctic and Subantarctic, experienced moderate, decelerating thinning $\left(-0.19 \pm 0.05 \mathrm{~m} \mathrm{yr}^{-1}\right)$ in line with recent gravimetric surveys of the entire Peninsula ${ }^{25}$.

Only two regions of the world beyond the ice sheet peripheries experienced slowdown of glacier thinning. Icelandic glaciers' record thinning rates during 2000-2004 $(1.21 \pm 0.18 \mathrm{~m}$ $\left.\mathrm{yr}^{-1}\right)$ were nearly halved during 2015-2019 $\left(0.77 \pm 0.13 \mathrm{~m} \mathrm{yr}^{-1}\right)$, which coincides with the decelerated thinning of Scandinavian glaciers. Both are well-corroborated by in-situ observations $^{21}$. Taken together, the slowdown in mass loss from these two regions, in addition to the one of peripheral glaciers of southeast Greenland Periphery ${ }^{32}$, define a regional pattern that we refer to as the North Atlantic anomaly.

Elsewhere on Earth, glacier thinning accelerated. The combined mass loss of these regions

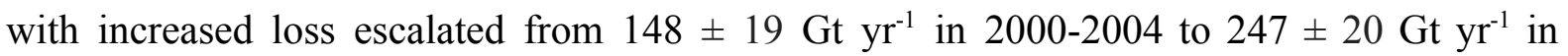
2015-2019. Two-thirds of this increase derives from three regions: Alaska (38\%), High Mountain Asia (19\%), and Western Canada and US (9\%). Glaciers in the latter region experienced a fourfold increase in thinning rates. Most notably, glaciers in Northwestern America (Alaska, Western Canada and US) are responsible for nearly $50 \%$ of the accelerated mass loss. The widespread and strong increase of thinning of High Mountain Asian glaciers brought a large sub-region of sustained thickening in central-western Asia down to a generalized thinning in the late 2010s (Extended Data Fig. 7), suggesting the end of the so-called Karakoram anomaly ${ }^{10}$. Smaller glacierized regions also underwent strong, sometimes drastic acceleration of thinning. New Zealand, for example, shows a record $1.52 \pm$ $0.50 \mathrm{~m} \mathrm{yr}^{-1}$ thinning rate in 2015-2019, which is a nearly sevenfold increase compared to 2000-2004.

Analysis of climate data reveals that much of the regional patterns of mass change uncovered by our resolved estimates are consistent with large-scale, decadal changes in annual precipitation and temperature (Fig. 4b,c). Strong dipoles that reflect concordant spatial patterns between precipitation change and mass change are observed notably in Northwestern America, southern Greenland Periphery and the Southern Andes. The southern Andean 
dipole is consistent with the mega-drought ${ }^{33}$ of the 2010s that drove increased glacier mass loss in the Central Andes. In the Coast Mountains of Western Canada and in southeast Alaska, glaciers were severely deprived of precipitation that instead benefited neighbouring regions of central Alaska and continental US, correspondingly showing either stable or reduced mass loss. The North Atlantic anomaly coincided with the cool, wet conditions of the last decade. Weaker dipoles can also be observed within the European Alps or Scandinavia. In both regions, glacier thinning slightly accelerated in the northeast and decelerated in the southwest.

While decadal changes in precipitation explain some of the observed regional anomalies, the global acceleration of glacier mass loss mirrors the global warming of the atmosphere. Aggregated globally over glacierized terrain, we observe modest trends in precipitation during the period 2000-2019 (0.002 $\mathrm{m} \mathrm{yr}^{-1},+6.2 \%$ in 20 years), whereas we detect a strong increase in air temperature $\left(0.030 \mathrm{~K} \mathrm{yr}^{-1}\right)$. Combined with our estimate of accelerated mass change, this warming trend yields an observational global glacier mass balance sensitivity of $-0.27 \mathrm{~m}$ w.e. $\mathrm{yr}^{-1} \mathrm{~K}^{-1}$, in agreement with modelling-based estimates ${ }^{34}$. Previous studies ${ }^{35}$ have indicated large multi-decadal variation in rates of glacier mass change across the 20th century, implying that some of the acceleration we observe could fall within the range of natural variability. Nonetheless, the strong concordance to the increase in global surface temperatures suggests, indirectly, a considerable response to anthropogenic forcing. Together, the contrasting patterns and global-scale sensitivities consistent with meteorological conditions support the notion of a long-term, temperature-driven acceleration in glacier mass $\operatorname{loss}^{13}$ that is still subject to regional and sub-decadal precipitation-driven fluctuations of large magnitude.

\section{Two decades of observational wealth}

Benefiting from the nearly complete spatial coverage afforded by ASTER stereo-imagery, our global estimate of recent glacier mass change $\left(-275 \pm 17 \mathrm{Gt} \mathrm{yr}^{-1}\right.$ for the 2006-2015 IPCC SROCC reference period) shows strongly reduced uncertainties compared to the latest IPCC

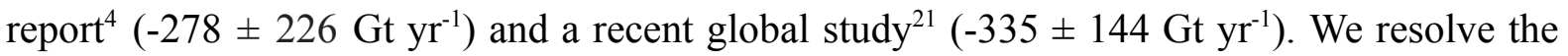
time-varying nature of this mass change signal for nearly all of Earth's glaciers which, globally, reveals a significant accelerated mass loss. Decadal rates of glacier mass change remain, however, strongly modulated by regional climatic conditions. We capture the magnitude of such fluctuations, most contrasted for North Atlantic and Northwestern American glaciers that evolved in opposing directions. At the end of the 2010s, the North Atlantic anomaly brought a whole subregion of eastern Greenland Periphery close to balance, while the strong increase in thinning rates of High Mountain Asian glaciers likely marks the end of the Karakoram anomaly.

From the spatiotemporally resolved nature of our assessment, novel possibilities arise to harness observations of the satellite era. Not only instrumental for glaciers, such resolved estimates also hold the potential to constrain recent ice sheet mass balance, in particular for the outlet glaciers that are prone to the highest long-term sea-level rise. The improved ability to deconvolve glacier signals from gravimetric observations might foster the detection of nearly two decades of changes in terrestrial water storage. In time, we expect our 
observational baseline to help drive the development of the next generation of global glaciological and hydrological models, and to ultimately result in more reliable projections at all scales ${ }^{14}$. In light of the rapid, ongoing change of the cryosphere, the increasingly reliable projections made possible by accurate, global-scale observations are critical for the design of adaptation strategies, with impacts ranging from further sea-level rise ${ }^{4,11}$ to changes in water management for some of the most vulnerable regions on Earth ${ }^{12,15}$.

1. Pritchard, H. D. Asia's shrinking glaciers protect large populations from drought stress. Nature 569, 649-654 (2019).

2. WCRP Global Sea Level Budget Group. Global sea-level budget 1993-present. Earth Syst. Sci. Data 10, 1551-1590 (2018).

3. Stoffel, M. \& Huggel, C. Effects of climate change on mass movements in mountain environments. Progress in Physical Geography: Earth and Environment 36, 421-439 (2012).

4. Pörtner, H. O. et al. IPCC Special Report on the Ocean and Cryosphere in a Changing Climate. IPCC Intergovernmental Panel on Climate Change: Geneva, Switzerland (2019).

5. Gardner, A. et al. A reconciled estimate of glacier contributions to sea level rise: 2003 to 2009. Science 340, 852-857 (2013).

6. Nerem, R. S. et al. Climate-change-driven accelerated sea-level rise detected in the altimeter era. Proc. Natl. Acad. Sci. U. S. A. 115, 2022-2025 (2018).

7. IMBIE Team. Mass balance of the Greenland Ice Sheet from 1992 to 2018. Nature 579, 233-239 (2020).

8. IMBIE team. Mass balance of the Antarctic Ice Sheet from 1992 to 2017. Nature 558, 219-222 (2018).

9. Smith, B. et al. Pervasive ice sheet mass loss reflects competing ocean and atmosphere processes. Science 368, 1239-1242 (2020).

10. Kääb, A., Berthier, E., Nuth, C., Gardelle, J. \& Arnaud, Y. Contrasting patterns of early twenty-first-century glacier mass change in the Himalayas. Nature 488, 495-498 (2012).

11. Kulp, S. A. \& Strauss, B. H. New elevation data triple estimates of global vulnerability to sea-level rise and coastal flooding. Nat. Commun. 10, 4844 (2019).

12. Immerzeel, W. W. et al. Importance and vulnerability of the world's water towers. Nature 577, 
364-369 (2020).

13. Marzeion, B., Cogley, J. G., Richter, K. \& Parkes, D. Attribution of global glacier mass loss to anthropogenic and natural causes. Science 345, 919-921 (2014).

14. Huss, M. \& Hock, R. Global-scale hydrological response to future glacier mass loss. Nat. Clim. Chang. (2018) doi:10.1038/s41558-017-0049-x.

15. IPCC. Climate Change 2014: Impacts, Adaptation, and Vulnerability. Part B: Regional Aspects. (Cambridge University Press, 2014).

16. Cauvy-Fraunié, S. \& Dangles, O. A global synthesis of biodiversity responses to glacier retreat. Nat Ecol Evol 3, 1675-1685 (2019).

17. World Glacier Monitoring Service (WGMS). Fluctuations of Glaciers Database. (2019) doi:10.5904/WGMS-FOG-2019-12.

18. Bamber, J. L., Westaway, R. M., Marzeion, B. \& Wouters, B. The land ice contribution to sea level during the satellite era. Environ. Res. Lett. 13, (2018).

19. Wouters, B., Gardner, A. S. \& Moholdt, G. Global Glacier Mass Loss During the GRACE Satellite Mission (2002-2016). Front. Earth Sci. 7, 535 (2019).

20. Ciracì, E., Velicogna, I. \& Swenson, S. Continuity of the Mass Loss of the World's Glaciers and Ice Caps From the GRACE and GRACE Follow-On Missions. Geophys. Res. Lett. 47, 226 (2020).

21. Zemp, M. et al. Global glacier mass changes and their contributions to sea-level rise from 1961 to 2016. Nature 568, 382-386 (2019).

22. RGI Consortium. Randolph Glacier Inventory - A Dataset of Global Glacier Outlines: Version 6.0: Technical Report, Global Land Ice Measurements from Space, Colorado, USA. (2017) doi:10.7265/N5-RGI-60.

23. Huss, M. Density assumptions for converting geodetic glacier volume change to mass change. The Cryosphere 7, 877-887 (2013).

24. Ablain, M. et al. Uncertainty in satellite estimates of global mean sea-level changes, trend and acceleration. Earth System Science Data 11, 1189-1202 (2019).

25. Velicogna, I. et al. Continuity of Ice Sheet Mass Loss in Greenland and Antarctica From the 
GRACE and GRACE Follow-On Missions. Geophys. Res. Lett. 47, L11501 (2020).

26. Larsen, C. F. et al. Surface melt dominates Alaska glacier mass balance. Geophys. Res. Lett. 42, 5902-5908 (2015).

27. Blazquez, A. et al. Exploring the uncertainty in GRACE estimates of the mass redistributions at the Earth surface: implications for the global water and sea level budgets. Geophys. J. Int. 215, $415-430(2018)$.

28. Shean, D. E. et al. A Systematic, Regional Assessment of High Mountain Asia Glacier Mass Balance. Front. Earth Sci. 7, 435 (2020).

29. Braun, M. H. et al. Constraining glacier elevation and mass changes in South America. Nat. Clim. Chang. (2019) doi:10.1038/s41558-018-0375-7.

30. Dehecq, A. et al. Elevation Changes Inferred From TanDEM-X Data Over the Mont-Blanc Area: Impact of the X-Band Interferometric Bias. IEEE Journal of Selected Topics in Applied Earth Observations and Remote Sensing 9, 3870-3882 (2016).

31. Sandberg Sørensen, L. et al. 25 years of elevation changes of the Greenland Ice Sheet from ERS, Envisat, and CryoSat-2 radar altimetry. Earth Planet. Sci. Lett. 495, 234-241 (2018).

32. Bevis, M. et al. Accelerating changes in ice mass within Greenland, and the ice sheet's sensitivity to atmospheric forcing. Proc. Natl. Acad. Sci. U. S. A. 116, 1934-1939 (2019).

33. Garreaud, R. D. et al. The Central Chile Mega Drought (2010-2018): A climate dynamics perspective. Int. J. Climatol. 40, 421-439 (2020).

34. Raper, S. C. B. \& Braithwaite, R. J. Low sea level rise projections from mountain glaciers and icecaps under global warming. Nature 439, 311-313 (2006).

35. Parkes, D. \& Marzeion, B. Twentieth-century contribution to sea-level rise from uncharted glaciers. Nature 563, 551-554 (2018).

36. Becker, J. J. et al. Global Bathymetry and Elevation Data at 30 Arc Seconds Resolution: SRTM30_PLUS. Mar. Geod. 32, 355-371 (2009). 


\begin{tabular}{|c|c|c|c|c|c|c|c|c|c|c|c|c|c|c|c|c|}
\hline \multirow[b]{3}{*}{ Glaciers } & \multirow{3}{*}{\begin{tabular}{|l} 
Reference \\
This study \\
\end{tabular}} & \multicolumn{15}{|c|}{ Mass change rate (Gt $y^{-1}$ ) } \\
\hline & & \multicolumn{3}{|c|}{ 2000-2004 } & \multicolumn{3}{|c|}{ 2005-2009 } & \multicolumn{2}{|c|}{ 2010-2014 } & \multicolumn{2}{|c|}{ 2015-2018* } & \multicolumn{3}{|c|}{ 2000-2018* } & \multicolumn{2}{|c|}{ 2003-2018* } \\
\hline & & -227 & \pm 2 & 25 & -257 & \pm 2 & 22 & -284 & \pm 23 & -292 & \pm 24 & -264 & \pm 1 & 16 & -272 & \pm 16 \\
\hline \multirow{2}{*}{$\begin{array}{l}\text { Greenland } \\
\text { Ice Sheet }\end{array}$} & $\begin{array}{l}\text { IMBIE }{ }^{7} \text { minus This study } \\
\text { (Greenland Periphery) }\end{array}$ & -94 & \pm 6 & 65 & -206 & \pm 5 & 56 & -267 & \pm 57 & -152 & \pm 64 & -181 & \pm 3 & 31 & -205 & \pm 32 \\
\hline & Smith et al. ${ }^{9}$ & & & & & & & & & & & & & & -200 & \pm 24 \\
\hline \multirow{2}{*}{$\begin{array}{l}\text { Antarctic } \\
\text { Ice Sheet }\end{array}$} & $\begin{array}{l}\text { IMBIE }{ }^{7} \text { minus This study } \\
\text { (Antarctic and Subantarctic) }\end{array}$ & -36 & \pm 1 & 118 & -93 & \pm 1 & 104 & -214 & \pm 94 & -157 & \pm 87 & -121 & \pm 1 & 104 & -143 & \pm 104 \\
\hline & Smith et al. ${ }^{9}$ & & & & & & & & & & & & & & -118 & \pm 48 \\
\hline
\end{tabular}

\section{Table 1. Separating mass losses of glaciers and ice sheets.}

Mass losses from glaciers, the GIS and AIS with 95\% confidence intervals. Half of the peripheral glacier component estimated in this study is removed from the ensemble estimates of the ice sheet mass balance inter-comparison exercise (IMBIE) ${ }^{7,8}$, see Methods. ${ }^{*}$ The end date is $06 / 2017$ for the AIS IMBIE estimate.

\section{Fig. 1. Regional glacier mass changes and their temporal evolution from 2000 to 2019.}

Regional and global mass change rates with time series of mean surface elevation change rates for glaciers (indigo) of the 19 first-order RGI $6.0^{22}$ regions (white-delimited polygons), shown on top of a world hillshade ${ }^{36}$. Regions 2, 5, 9, 17 are further divided to illustrate contrasted temporal patterns. Mass change rates are represented by the area of the disk delimiting the inside wedge, which separates the mass change contribution of land-terminating (light grey) and marine-terminating glaciers (light

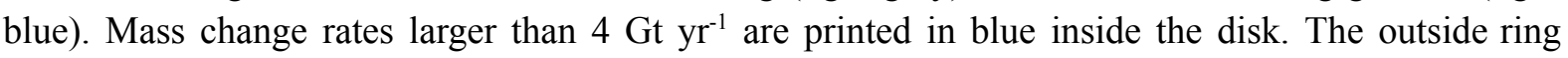
discerns between land (grey) and marine-terminating (blue) glacier area. Annual time series of mean elevation change and regional data coverage are displayed on time friezes at the bottom of the disks.

\section{Fig. 2. Spatial distribution of glacier elevation change between 2000 and 2019.}

Glacier mean elevation change rate is aggregated for tiles of $1^{\circ} \times 1^{\circ}$ below $60^{\circ}$ latitude, $2^{\circ} \times 1^{\circ}$ between $60^{\circ}$ and $74^{\circ}$ latitude and $2^{\circ} \times 2^{\circ}$ above $74^{\circ}$ latitude, thus representing similar surface areas of approximately $10,000 \mathrm{~km}^{2}$. Disks scale with the glacierized area of each tile and are colored according to the mean elevation change rate (colored in grey if less than $50 \%$ surface is covered by observations or if the $95 \%$ confidence interval is larger than $1 \mathrm{~m} \mathrm{yr}^{-1}$; only applies to $0.4 \%$ of the glacierized area) shown on top of a world hillshade ${ }^{36}$. Tiles with glacierized areas below or equal to $10 \mathrm{~km}^{2}$ are displayed at the same minimum size.

\section{Fig. 3. Comparison to earlier global estimates.}

Regional and global specific mass change rates with $95 \%$ confidence intervals (s.e.m). a, Estimates from earlier studies ${ }^{5,19-21}$ (colored) and the estimates from this study over corresponding time periods (black). b, Global estimates of earlier studies with annual and 5-year rates of this study. Annual rates of earlier studies are not shown due to large uncertainties. Uncertainties from this study are conservative, in particular for regions with most negative specific rates (see Methods). 
Fig. 4. Decadal patterns of glacier thinning are consistent with decadal variations in precipitation and temperature.

Difference between 2010-2019 and 2000-2009 for the mean elevation change rates from this study (a) and the mean annual precipitation (b), mean annual temperature (c) from ERA5. Region inset numbering corresponds to Fig. 2 . Tiles are $1^{\circ} \times 1^{\circ}$ with size inversely scaled to uncertainties in the mean elevation change difference shown on top of a world hillshade ${ }^{36}$. Minimum tile area is $10 \%$ for 95\% CI larger than $1 \mathrm{~m} \mathrm{yr}^{-1}$ and tiles are displayed at full size for 95\% CI smaller than $0.4 \mathrm{~m} \mathrm{yr}^{-1}$.

\section{Methods}

We summarize the workflow used to process elevation datasets into estimates of glacier mass change for the period of January 1, 2000 to December 31, 2019 (Extended Data Fig. 1).

\section{Glacier inventories}

We used the Randolph Glacier Inventory 6.022 (RGI) outlines for all regions except for Caucasus Middle East (region 12). Due to the high number of uncharted ("nominal") glaciers in that region, we updated our inventory with the latest Global Land Ice Measurements from Space (GLIMS) outlines available ${ }^{37}$. This increased the number of glacier outlines in region 12 from 1,888 to 3,516, representing an increase in total area from 1,307 to $1,336 \mathrm{~km}^{2}$. In Svalbard and Jan Mayen (region 7), we manually updated glacier outlines to account for advances resulting from major surges ${ }^{38-40}$, increasing mapped areas by $228 \mathrm{~km}^{2}$ (Extended Data Fig. 6). In the Greenland Periphery (region 5), we did not analyze the 955 glaciers strongly connected to the ice sheet (RGI connectivity level 2) with an area of $40,354 \mathrm{~km}^{2}$, as these are generally included within the ice sheet by studies on the GIS ${ }^{7,9}$. Our updated inventory numbers 217,175 glaciers, covering a total area of $705,997 \mathrm{~km}^{2}$. For the purpose of co-registering and bias correcting DEMs, we masked ice-covered terrain using the RGI for glaciers, the Greenland Ice Mapping Project ${ }^{41}$ for the GIS, and Bedmap $2^{42}$ for the AIS.

\section{Digital elevation models}

We retrieved all $\mathrm{ASTER}^{43}$, ArcticDEM ${ }^{44}$ and Reference Elevation Model of Antarctica ${ }^{45}$ (REMA) data intersecting glaciers worldwide (Extended Data Fig. 2), totalling more than 100 TB of data storage. Because of the non-negligible effects of radar penetration into snow and ice $^{30}$, we excluded radar elevation datasets from our analysis except for the TanDEM-X $90 \mathrm{~m}$ global DEM ${ }^{46}$ (TanDEM-X). We used TanDEM-X as a globally homogeneous reference ${ }^{47}$ for co-registration $^{48}$ and bias correction over ice-free terrain, keeping only elevations with an error smaller than $0.5 \mathrm{~m}$ in the provided TanDEM-X height error map. For all DEMs bilinearly resampled to $30 \mathrm{~m}$, co-registration was performed only if more than 100 valid elevation differences (slope $>3$ degrees, absolute elevation difference $<200 \mathrm{~m}$ ) were available at each iterative step.

From 440,548 ASTER L1A stereo-images ${ }^{43}$ (each covering $60 \mathrm{~km}$ by $60 \mathrm{~km}$ ), we generated, co-registered and bias-corrected 154,656 ASTER DEM strips ( $30 \mathrm{~m}$ resolution; $180 \mathrm{~km}$ by 60 $\mathrm{km}$ strip size) using improved techniques of MicMac for ASTER $^{49,50}$. Novel improvements were made by adjusting the back-looking image for cross-track biases before stereo 
calculations, by accounting for the curved along-track angle of the satellite Terra, and by stitching the arbitrarily-split $60 \mathrm{~km}$ x $60 \mathrm{~km}$ archive granules into longer strips. The latter operation mitigates edge effects and increases the amount of ice-free terrain available for improved basin-hopping optimizations ${ }^{51}$ of along-track undulations and satellite jitter parameters. Further details on the processing of ASTER DEMs are available in the Supplementary Information.

From 97,649 release 7 ArcticDEM ${ }^{44}$ DEMs at $2 \mathrm{~m}$ resolution and 13,790 release $1.1 \mathrm{REMA}^{45}$ DEMs at 2 and $8 \mathrm{~m}$ resolution, we stitched and co-registered 40,391 ArcticDEM and 3,456 REMA longer strips to TanDEM-X. Our stitching of the original DEM segments, generated by the Polar Geospatial Center using the Surface Extraction with TIN-based Search-space Minimization algorithm ${ }^{52}$, was performed by a sequential pairwise co-registration between same-day acquisitions over all available terrain. This procedure was necessary to increase the amount of ice-free terrain in the final DEM strip for co-registration to TanDEM-X. We allowed for a maximum standard deviation of co-registered elevation differences of $10 \mathrm{~m}$ before stopping the sequential co-registration iteration and starting a new strip, instead of the $1 \mathrm{~m}$ root-mean-square error originally used ${ }^{44,45}$.

\section{Elevation time series}

Following co-registration, we excluded all DEMs for which the root-mean-square error of the elevation difference with TanDEM-X on ice-free terrain was larger than $20 \mathrm{~m}$. Using all remaining DEMs, we created three-dimensional arrays (time $t$, space $x$ and $y$ ) of elevation $h(t, x, y)$, divided into $2,1061 \times 1^{\circ}$ tiles containing glaciers and downsampled to $100 \mathrm{~m}$ to decrease computing time.

In order to filter and interpolate our DEMs into elevation time series, we empirically characterized the spatial and temporal variance of elevation observations. For this, two global-scale statistical modelling steps relying on a large sampling of the data were performed. One was used to assess the vertical precision of elevation observations and the other to assess their pairwise dependency with varying time lags (Extended Data Fig. 3a,b).

Concomitantly to the variance modelling process described further below, a multi-step outlier filtering is performed to iteratively improve the quality of the DEMs (Extended Data Fig. 1), which itself affects the empirical estimation of the variances. The filtering algorithms consist of a spatial filter, removing elevations outside a topographical maximum and minimum from the TanDEM-X elevations in the pixel surroundings, and a temporal filter propagated from the TanDEM-X elevation at a given pixel through a maximum possible glacier elevation change rate (Extended Data Fig. 3c). These maximums were first conditioned by extreme values (e.g., maximum observed absolute glacier elevation change of $50 \mathrm{~m} \mathrm{yr}^{-1}$ on HPS12 glacier, Southern Patagonian Icefield ${ }^{53}$ ). Later, those were refined by estimating a linear glacier elevation change in the surroundings through weighted least-squares ${ }^{54}$.

In our first global-scale statistical modelling step, we identified an heteroscedasticity in elevation measurements (i.e., non-uniform variance, Extended Data Fig. 3a). We determined that the elevation measurement error $\sigma_{h}$ varied with the terrain slope ${ }^{55,56} \alpha$, the quality of stereo-correlation $^{49,57} q$ and the individual performance of each DEM's co-registration ${ }^{48}$ 
$\sigma_{c}(t, x, y)$. To empirically quantify this elevation variance, we used ice-free terrain, where no changes in elevation are expected through time, as a proxy for ice-covered terrain. We randomly sampled up to 10,000 ice-free pixels without replacement for each bin of a studied category of terrain (e.g., slope) in each $1 \times 1^{\circ}$ tile and computed the difference to TanDEM-X. We used the median as a robust estimator of the mean and the square of the Normalized Median Absolute Deviation (NMAD) as a robust estimator of the variance to mitigate the effects of elevation outliers ${ }^{58}$. We found that the empirical variances for the slope $\sigma_{\alpha}{ }^{2}$ and the quality of stereo-correlation $\sigma_{q}{ }^{2}$ were consistent among regions, and used them to condition a model at the global scale to account for the measurement error independently for each elevation observation $h(t, x, y)$ :

$\sigma_{h}(t, x, y)^{2}=\sigma_{c}(t, x, y)^{2}+\sigma_{\alpha}(\alpha, q)^{2}+\sigma_{q}(q)^{2}$

In our second step of global-scale statistical modelling, we determined the temporal covariance of glacier elevation change (Extended Data Fig. 3b), which serves as our best-unbiased estimator to interpolate elevation observations into continuous time series through Gaussian Process ${ }^{59}$ (GP) regressions. To empirically quantify this temporal covariance, we sampled median temporal variograms by time lag between pairwise elevation observations $\Delta t$ of ice-covered pixels. We found that the covariance structure could be estimated by the sum of a pairwise linear (PL) kernel, a periodic (exponential-sine-squared, ESS) kernel, a local (radial basis function, RBF) kernel, and the product of a pairwise linear and local (rational quadratic, RQ) kernel. This sum decomposes the differences of elevation observations with varying time lags into: an underlying linear trend (the PL), a seasonality (the ESS), a proximity at short time lags (the RBF) and a non-linear trend (the RQ times PL). Empirical covariances showed little variability between regions. We thus conditioned the parameters of the ESS, RBF and RQ kernels $\left(\phi_{p}, \sigma_{p}, \Delta t_{l}, \sigma_{l}, \Delta t_{n l}, \sigma_{n l}\right.$ and $\left.\alpha_{n l}\right)$ at the global scale based on our empirical variograms, while the PL kernel was determined directly from the observations of each pixel $(x, y)$ :

$\sigma_{h}(x, y, \Delta t)^{2}=P L(x, y, \Delta t)+\operatorname{ESS}\left(\phi_{p}, \sigma_{p}^{2}, \Delta t\right)+R B F\left(\Delta t_{l}, \sigma_{l}^{2}, \Delta t\right)+$

$R Q\left(\Delta t_{n l}, \sigma_{n l}^{2}, \alpha_{n l}, \Delta t\right) \cdot P L(x, y, \Delta t)+\underset{h}{\sigma}(t, x, y)^{2}$

Applying GP regression, we iteratively removed observations outside the 20-, 12-, 9-, 6- and 4-sigma credible intervals (Extended Data Fig. 3d). Within the same process, elevation time series were then derived at a monthly time step independently for each of the 400 millions pixels $(x, y)$ falling on or within $10 \mathrm{~km}$ of an inventoried glacier ${ }^{22}$ (Extended Data Fig. 3e). Further details on the variance estimation, filtering and time series methods are available in the Supplementary Information and build on additional references ${ }^{60-63}$. 


\section{Validation of elevation time series}

We retrieved all ICESat (GLAH14 ${ }^{64}$ ) and IceBridge (IODEM $3^{65}$ and ILAKS1B ${ }^{66}$ ) laser and optical elevations intersecting glaciers worldwide from the National Snow and Ice Data Center. IceBridge data are dominated by 1,220,494 Ames Stereo Pipeline ${ }^{67}$ photogrammetric $0.5-2 \mathrm{~m}$ resolution DEMs ${ }^{65}$ with a typical footprint of $500 \mathrm{~m} \times 500 \mathrm{~m}$ that we downsampled to a resolution of $50 \mathrm{~m}$ to limit repeat spatial sampling when comparing to the $100 \mathrm{~m}$ resolution of our elevation time series. We linearly interpolated our GP elevation time series in space and time to match the date and center of each ICESat footprint or IceBridge pixel ${ }^{68}$ (Extended Data Fig. 4a-c).

We found that regional and seasonal vertical shifts (typically below $2 \mathrm{~m}$ ) of surface elevation exist, and attribute these differences to snow cover in the TanDEM-X global DEM ${ }^{46}$ and the presence of seasonally-varying snow cover in ASTER, ArcticDEM and REMA DEMs. At the global scale, these shifts do not impact our annual estimates once differenced into elevation change, verified by the absence of elevation change bias over glaciers $\left(0.001 \pm 0.011 \mathrm{~m} \mathrm{yr}^{-1}\right)$. We additionally demonstrated that the uncertainties in our elevation time series (credible interval of the Gaussian Process regression) are conservative (i.e. too large by a factor of about two). We reached the same conclusions at the scale of individual RGI regions, and also performed these verifications with several additional relevant variables (Extended Data Fig. 4d). In particular, the absence of a bias with glacier elevation denotes our ability to adequately resolve low-texture glacier surfaces in the accumulation area including flat, high-latitude ice caps. Further details on the validation of elevation time series are available in the Supplementary Information and build on an additional reference ${ }^{69}$.

\section{Integration of elevation into volume changes}

We differenced all elevations $h$ into elevation change based on their value of $h$ on January 1st, 2000. We integrated elevation change $d h$ into volume change $d V$ independently for each glacier and time step using a weighted version of the mean local hypsometric method ${ }^{70}$ with $100 \mathrm{~m}$ elevation bins. Weights were derived from the GP elevation change uncertainties, hence assuring that pixels with a lower vertical precision in a given elevation bin have a smaller impact on the mean elevation change of that bin. Pixels with a 20-year elevation change larger than five times the NMAD from the median elevation change of the elevation bin were removed ${ }^{53}$. If no valid elevation estimate existed within a given bin, elevation change was linearly interpolated from adjacent bins, or extrapolated from the closest bins. For retreating lake- and ocean- terminating glaciers, we exclude any loss below water level, because DEMs refer to the water surface and not the poorly known bathymetry in the deglaciated terrain. We note that these losses do not contribute to sea-level rise.

\section{Uncertainty analysis of volume changes}

We propagated our uncertainties in elevation change into uncertainties in volume change uncertainties by assuming that the uncertainty in the mean elevation change $\sigma_{\overline{d h}}$ and the uncertainty in the glacier area $\sigma_{A}$ are independent: 
$\sigma_{d V}^{2}=\left(\sigma_{\overline{d h}} A\right)^{2}+\left(\sigma_{A} \overline{d h}\right)^{2}$

The uncertainty in the mean elevation change $\sigma_{\overline{d h}}$ is highly subject to spatial correlations due to instrument resolution (spatial scale of 0-150 m), uncorrected ASTER instrument noise ${ }^{50}$ $(0-20 \mathrm{~km})$, and the interpolated nature of our elevation time series $(0-500 \mathrm{~km})$. The latter spatial correlation term arises from neighboring pixels of a given region sharing similar temporal data gaps, and are hence likely to have similar interpolation biases which correspond to long-range correlations. To empirically quantify these three sources of spatial correlations, we drew spatial variograms of elevation differences between ICESat and our GP elevation time series ${ }^{71}$ at each ICESat acquisition date. We found that the spatial correlations greatly varied with the time lag $\Delta t$ to the closest ASTER, ArcticDEM or REMA observation. For each time lag, we estimated the partial sill $s_{k}$ (correlated variance) by fitting a sum of seven spherical variogram models $S\left(d, s_{k}, r_{k}\right)$, with $d$ the spatial lag, at ranges $r_{k}$ (correlation lengths) of $0.15 \mathrm{~km}, 2 \mathrm{~km}, 5 \mathrm{~km}, 20 \mathrm{~km}, 50 \mathrm{~km}, 200 \mathrm{~km}$ and $500 \mathrm{~km}$ (Extended Data Fig. $5 \mathrm{a}, \mathrm{b})$. To propagate these spatial correlations when integrating glacier volumes, we computed the time lag to the closest ASTER, ArcticDEM or REMA observation for each time step of our elevation time series and for each glacier pixel to estimate $s_{1}$ to $s_{6}$. We then used the GP elevation change uncertainties of each glacier pixel to derive $s_{0}$. Finally, we propagated the pixel-wise uncertainties in elevation change into the uncertainty in the mean elevation change $\sigma_{\overline{d h}}$ by circular integration of the sum of variograms ${ }^{72}$ over the glacier area $A$ (Extended Data Fig. 5c):

$\sigma_{\overline{d h}^{2}}{ }^{2}=\frac{1}{A} \sum_{k=0}^{6} \sigma_{\overline{d h}_{k}}^{2}$

where $\sigma_{\overline{d h}_{k}}$ is the integrated variance component correlated with range $r_{k}$ :

$\sigma_{\overline{d_{k}}}^{2}=\int_{A}\left(s_{k}-S\left(d, s_{k}, r_{k}\right)\right) d A$

The reliability of the sum of short-range correlations used to account for uncorrected ASTER instrument noise $(0-20 \mathrm{~km})$ was further verified by applying empirical methods to ice-free terrain $^{73}$ and found to yield larger and more realistic uncertainty estimates than the single range variograms of $0.2-1 \mathrm{~km}$ used in previous studies ${ }^{28,53,54,74-76}$. Our maximum correlation length of $500 \mathrm{~km}$ accords with known spatial correlations of mass balance estimates ${ }^{77}$. Further details on the spatial correlation methods are available in the Supplementary Information and build on additional references ${ }^{78-83}$. 
For each glacier, we estimated an uncertainty in the area $\sigma_{A}$ based on a buffer ${ }^{84}$ of $15 \mathrm{~m}$ corresponding to the typical resolution of the optical imagery used to derive these outlines ${ }^{37,85-87}$. These uncertainties vary from about $0.1 \%$ of the area for large icefields $(>1000$ $\left.\mathrm{km}^{2}\right)$ to $50 \%$ of the area and above for small isolated glaciers $\left(<0.1 \mathrm{~km}^{2}\right)$.

\section{Validation of volume changes}

We retrieved high-resolution DEMs from LiDAR $^{74,88}$, Pléiades ${ }^{54,89}$, Satellite Pour l'Observation de la Terre ${ }^{90,91}$ and aerial photographs ${ }^{92,93}$ acquired in Alaska, Western North America, Central Europe and High Mountain Asia between 2000 and 2019. We derived precise volume change estimates during specific periods for 588 glaciers covering $3,300 \mathrm{~km}^{2}$ and compared these to our volume time series extracted over the same glaciers and periods. We found no statistically significant bias of mean elevation change $\left(0.03 \pm 0.03 \mathrm{~m} \mathrm{yr}^{-1}\right.$, Extended Data Fig. 5d). We then validated that our uncertainties, derived from spatially integrated variograms calibrated on ICESat measurements, matched the empirical errors deduced from the comparison ( $\sim 92 \%$ of $95 \%$ uncertainty ranges intersect the high-precision volume changes, Extended Data Fig. 5d-f). On average, our 5-year 95\% uncertainties are lower than $0.3 \mathrm{~m} \mathrm{yr}^{-1}$ for glaciers larger than $1 \mathrm{~km}^{2}$ and conservative for smaller glaciers. We thus validated the reliability of our improved uncertainty approaches for volume change estimation down to the scale of individual glaciers.

\section{Aggregation to regions}

We summed volume changes of glaciers per region. To propagate correlated uncertainties between glaciers of the same region, we extend the spatial statistics approach used at the glacier scale. For each time step, glacier-wide correlated uncertainties were propagated again to yield an uncertainty in the mean regional elevation change $\sigma_{\overline{d h}_{R}}$. Having been integrated once over a spatial support (from pixel to glacier), the glacier-wide errors can be propagated again (from glacier to regions) directly by a double sum of covariances based on the same describing variograms, following Krige's relation ${ }^{71}$ :

$\sigma_{\overline{d h_{R}}}^{2}=\frac{1}{A_{R}^{2}} \cdot \sum_{i} \sum_{j} \sum_{k=0}^{6}\left(\sigma_{\overline{d h_{k, i}}} \sigma_{\overline{d h_{k, j}}}-S\left(G_{i}-G_{j}, \sigma_{\overline{d h_{k, i}}} \sigma_{\overline{d h_{k, j}}}, r_{k}\right)\right) A_{i} A_{j}$

where $i, j$ are indexes for glaciers in the region, $\sigma_{\overline{d h_{k, i}}}$ is the uncertainty in the mean elevation change $\sigma_{\overline{d h}_{k}}$ with range $r_{k}$ and sill $s_{k}$ for glacier i, $G_{i}-G_{j}$ is the pairwise distance (spatial lag $d$ ) between glaciers $i$ and $j$ based on their outline centroids and $A_{i}$ is the area of glacier $i$.

\section{Conversion to mass changes}

We converted volume change into mass change by using a density conversion factor ${ }^{23}$ of 850 $\mathrm{kg} \mathrm{m}^{-3}$ and an uncertainty of $60 \mathrm{~kg} \mathrm{~m}^{-3}$. This density conversion uncertainty was applied at the 
scale of RGI regions, as if correlated for all glaciers in the entire region, an assumption that yields more conservative estimates than earlier studies ${ }^{29,54}$. We made this conversative assumption due to the limited knowledge of spatiotemporal correlations in density conversion. Consequently, our mass change uncertainties might be too large, in particular for regions with the most negative specific mass change rates (Fig. 3, Extended Data Fig. 5g,h).

\section{Aggregation to global}

We summed our regional volume and mass change estimates into global volume and mass change. Assuming independence of the uncertainty in volume and mass changes between RGI regions, we summed regional uncertainties quadratically. We report uncertainties in mass changes for periods shorter than five years solely for the global or near-global estimates (e.g. Fig. 3b) by assuming that the aggregation of largely independent RGI regions leaves limited temporal autocorrelation of density conversion factors. We compare our regional and global mass changes results with global and regional studies listed by the latest IPCC assessment ${ }^{4}$ as well as additional recent studies ${ }^{28,53,94-96}$ (Supplementary Table S4).

\section{Time-evolving glacier areas}

We accounted for temporal changes in glacier areas when deriving regional or global time series of specific (area-scaled) mass balances or mean elevation change (specific volume change). We assumed a linear change through time, calibrated on time-evolving glacier outlines of each RGI region ${ }^{21}$. Over the 20 -year study period, these time-evolving glacier areas correspond to a nearly $10 \%$ decrease of glacier areas around the globe, a non-negligible change when assessing mean elevation change rates. To account for this, we added an additional uncertainty in the time-evolving glacier area at each time step of $1 \%$ of the regional area at that time step.

\section{Observed sea-level rise}

We derived global mean sea-level trends from a recent study ${ }^{24}$ with time series extended to match our period of study of 2000-2019, yielding an estimate of sea-level rise of $3.56 \pm 0.4$ $\mathrm{mm} \mathrm{yr}^{-1}$ with an acceleration of $0.15 \pm 0.08 \mathrm{~mm} \mathrm{yr}^{-2}$. For conversion, we assumed that 361.8 Gt of water-equivalent mass loss amounted to $1 \mathrm{~mm}$ of sea-level rise.

\section{Acceleration}

Glacier mass change acceleration and its uncertainties were derived from weighted least-squares on the 5-year elevation and mass change rates (i.e., 2000-2004, 2005-2009, 2010-2014 and 2015-2019), propagating their related uncertainties as independent. While shorter time scales and smaller spatial domains are affected by temporal autocorrelation, we assumed the 5-year estimates at the global or near-global scale (i.e., excluding peripheral glaciers) as temporally uncorrelated. This assumption is supported by time scales described for density conversion factors ${ }^{23}$, by the validation of our elevation time series with ICESat and IceBridge, and relies on the billions of globally distributed surface elevation observations 
leading to large independent and repeat sampling over 5-year periods (Extended Data Table 2).

\section{Distinction between glaciers and ice sheets}

When comparing our results to ice sheet studies, we avoided double-counting contributions from peripheral glaciers by subtracting part of our own estimate for RGI regions 5 and 19 to ice sheet estimates from IMBIE ${ }^{7,8}$. Because IMBIE estimates are a weighted mean of three ensemble estimates where half include peripheral glaciers, the other half does not (gravimetric studies include peripheral glaciers, altimetric studies exclude peripheral glaciers, and input-output studies can do both), we assumed that subtracting half of our estimates for the peripheral glaciers was most adequate. Noteworthily, applying this subtraction leads to better agreement of GIS and AIS estimates between IMBIE and a recent study ${ }^{9}$ over the period 2003-2018 (Table 1).

\section{Temperature and precipitation analysis}

We analyzed ERA5 precipitation and temperature ${ }^{97}$ at both annual and seasonal scales. For the latter we consider only winter precipitation and summer temperature. We found similar decadal patterns at both annual and seasonal scales, and thus present annual changes (Fig. 4) to avoid the latitudinal ambiguity of glaciological definitions of seasons. Temperature change was extracted at $700 \mathrm{hPa}$ (about $3,100 \mathrm{~m}$ above sea level) to minimize variations in air temperature affected by differences in land surface class at the 0.125 degree nominal resolution of the ERA5 reanalysis. To estimate trends of annual precipitation and temperature over 2000-2019, we derived ordinary least-squares trends for each ERA5 grid cell containing glaciers. We then area-weighted the global trend by the glacierized area of each grid cell. We detect a small increase in precipitation at the global-scale (4.0\% in 20 years) and over glaciers (6.2\% in 20 years), coherent with the amplification of the global water cycle in a warming world near the Clausius-Clapeyron rate ${ }^{98}$. The sensitivity of mass change to air temperature was computed by dividing the specific mass change acceleration by the temperature increase over glacierized terrain for the period 2000-2019.

37. Tielidze, L. G. \& Wheate, R. D. The Greater Caucasus Glacier Inventory (Russia, Georgia and Azerbaijan). The Cryosphere 12, 81-94 (2018).

38. Dunse, T. et al. Glacier-surge mechanisms promoted by a hydro-thermodynamic feedback to summer melt. The Cryosphere 9, 197-215 (2015).

39. McMillan, M. et al. Rapid dynamic activation of a marine-based Arctic ice cap: Ice cap dynamic activation. Geophys. Res. Lett. 41, 8902-8909 (2014).

40. Nuth, C. et al. Dynamic vulnerability revealed in the collapse of an Arctic tidewater glacier. Sci. Rep. 9, 5541 (2019). 
41. Howat, I. M., Negrete, A. \& Smith, B. E. The Greenland Ice Mapping Project (GIMP) land classification and surface elevation data sets. The Cryosphere vol. 8 1509-1518 (2014).

42. Fretwell, P. et al. Bedmap2: improved ice bed, surface and thickness datasets for Antarctica. The Cryosphere 7, 375-393 (2013).

43. NASA/METI/AIST/Japan Spacesystems, and U.S./Japan ASTER Science Team. ASTER Level 1A Data Set - Reconstructed, unprocessed instrument data. (2001) doi:10.5067/ASTER/AST_L1A.003.

44. Porter, C. et al. ArcticDEM. (2018) doi:10.7910/DVN/OHHUKH.

45. Howat, I. M., Porter, C., Smith, B. E., Noh, M.-J. \& Morin, P. The Reference Elevation Model of Antarctica. The Cryosphere 13, 665-674 (2019).

46. Rizzoli, P. et al. Generation and performance assessment of the global TanDEM-X digital elevation model. ISPRS J. Photogramm. Remote Sens. 132, 119-139 (2017).

47. Vassilaki, D. I. \& Stamos, A. A. TanDEM-X DEM: Comparative performance review employing LIDAR data and DSMs. ISPRS J. Photogramm. Remote Sens. 160, 33-50 (2020).

48. Nuth, C. \& Kääb. Co-registration and bias corrections of satellite elevation data sets for quantifying glacier thickness change. The Cryosphere 5, 271-290 (2011).

49. Rupnik, E., Daakir, M. \& Pierrot Deseilligny, M. MicMac - a free, open-source solution for photogrammetry. Open Geospatial Data, Software and Standards 2, 14 (2017).

50. Girod, L., Nuth, C., Kääb, A., McNabb, R. \& Galland, O. MMASTER: Improved ASTER DEMs for Elevation Change Monitoring. Remote Sensing 9, 704 (2017).

51. Wales, D. J. \& Doye, J. P. K. Global Optimization by Basin-Hopping and the Lowest Energy Structures of Lennard-Jones Clusters Containing up to 110 Atoms. J. Phys. Chem. A 101, $5111-5116(1997)$.

52. Noh, M.-J. \& Howat, I. M. The Surface Extraction from TIN based Search-space Minimization (SETSM) algorithm. ISPRS J. Photogramm. Remote Sens. 129, 55-76 (2017).

53. Dussaillant, I. et al. Two decades of glacier mass loss along the Andes. Nat. Geosci. 12, 802-808 (2019).

54. Brun, F., Berthier, E., Wagnon, P., Kääb, A. \& Treichler, D. A spatially resolved estimate of High 
Mountain Asia glacier mass balances, 2000-2016. Nat. Geosci. 10, 668-673 (2017).

55. Toutin, T. Three-dimensional topographic mapping with ASTER stereo data in rugged topography. IEEE Trans. Geosci. Remote Sens. 40, 2241-2247 (2002).

56. Lacroix, P. Landslides triggered by the Gorkha earthquake in the Langtang valley, volumes and initiation processes the 2015 Gorkha, Nepal, Earthquake and Himalayan Studies: First Results 4. Seismology. Earth Planets Space 68, 1-10 (2016).

57. Shean, D. E. et al. An automated, open-source pipeline for mass production of digital elevation models (DEMs) from very-high-resolution commercial stereo satellite imagery. ISPRS J. Photogramm. Remote Sens. 116, 101-117 (2016).

58. Höhle, J. \& Höhle, M. Accuracy assessment of digital elevation models by means of robust statistical methods. ISPRS J. Photogramm. Remote Sens. 64, 398-406 (2009).

59. Williams, C. K. I. \& Rasmussen, C. E. Gaussian processes for machine learning. vol. 2 (MIT press Cambridge, MA, 2006).

60. Schiefer, E., Menounos, B. \& Wheate, R. Recent volume loss of British Columbian glaciers, Canada. Geophys. Res. Lett. (2007) doi:10.1029/2007GL030780.

61. Nuimura, T., Fujita, K., Yamaguchi, S. \& Sharma, R. R. Elevation changes of glaciers revealed by multitemporal digital elevation models calibrated by GPS survey in the Khumbu region, Nepal Himalaya, 1992-2008. J. Glaciol. 58, 648-656 (2012).

62. Willis, M. J., Melkonian, A. K., Pritchard, M. E. \& Rivera, A. Ice loss from the Southern Patagonian Ice Field, South America, between 2000 and 2012. Geophys. Res. Lett. 39, (2012).

63. Pedregosa, F. et al. Scikit-learn: Machine Learning in Python. J. Mach. Learn. Res. 12, $2825-2830(2011)$.

64. Zwally, H. J., Schutz, R., Hancock, D. \& Dimarzio, J. GLAS/ICESat L2 Global Land Surface Altimetry Data (HDF5), Version 34. (2014) doi:10.5067/ICESAT/GLAS/DATA211.

65. Alexandrov, O., McMichael, S. \& Beyer., R. A. IceBridge DMS L3 Ames Stereo Pipeline Photogrammetric DEM, Version 1. (2018).

66. Larsen, C. IceBridge UAF Lidar Scanner L1B Geolocated Surface Elevation Triplets, Version 1. (2010, updated 2020). 
67. Beyer, R. A., Alexandrov, O. \& McMichael, S. The Ames Stereo Pipeline: NASA's Open Source Software for Deriving and Processing Terrain Data. Earth and Space Science 5, 537-548 (2018).

68. Harding, D. J. ICESat waveform measurements of within-footprint topographic relief and vegetation vertical structure. Geophys. Res. Lett. 32, 2509 (2005).

69. Gardelle, J., Berthier, E. \& Arnaud, Y. Impact of resolution and radar penetration on glacier elevation changes computed from DEM differencing. J. Glaciol. 77, 121-128 (2012).

70. Mcnabb, R., Nuth, C., Kääb, A. \& Girod, L. Sensitivity of glacier volume change estimation to DEM void interpolation. The Cryosphere c, 895-910 (2019).

71. Cressie, N. A. C. Statistics for spatial data. vol. 4 613-617 (Wiley, 1993).

72. Rolstad, C., Haug, T. \& Denby, B. Spatially integrated geodetic glacier mass balance and its uncertainty based on geostatistical analysis: Application to the western Svartisen ice cap, Norway. J. Glaciol. 55, 666-680 (2009).

73. Dehecq, A. et al. Automated Processing of Declassified KH-9 Hexagon Satellite Images for Global Elevation Change Analysis Since the 1970s. Front Earth Sci. 8, 516 (2020).

74. Menounos, B. et al. Heterogeneous changes in western North American glaciers linked to decadal variability in zonal wind strength. Geophys. Res. Lett. 2018GL080942 (2018).

75. Howat, I. M., Smith, B. E., Joughin, I. \& Scambos, T. A. Rates of southeast Greenland ice volume loss from combined ICESat and ASTER observations. Geophys. Res. Lett. 35, 1-5 (2008).

76. Wang, D. \& Kääb, A. Modeling glacier elevation change from DEM time series. Remote Sensing 7, 10117-10142(2015).

77. Cogley, J. G. \& Adams, W. P. Mass balance of glaciers other than the ice sheets. J. Glaciol. 44, $315-325$ (1998)

78. Journel, A. G. \& Huijbregts, C. J. Mining geostatistics. vol. 600 (Academic press London, 1978).

79. Webster, R. \& Oliver, M. A. Geostatistics for Environmental Scientists. (2007).

80. Gräler, B., Pebesma, E. \& Heuvelink, G. Spatio-Temporal Interpolation using gstat. The $R$ Journal vol. 8204 (2016).

81. Mälicke, M. \& Schneider, H. D. Scikit-GStat 0.2.6: A scipy flavored geostatistical analysis 
toolbox written in Python. (2019). doi:10.5281/zenodo.3531816.

82. Dussaillant, I., Berthier, E. \& Brun, F. Geodetic Mass Balance of the Northern Patagonian Icefield from 2000 to 2012 Using Two Independent Methods. Front Earth Sci. 6, 8 (2018).

83. Berthier, E., Scambos, T. A. \& Shuman, C. A. Mass loss of Larsen B tributary glaciers (Antarctic Peninsula) unabated since 2002. Geophys. Res. Lett. 39, 1-6 (2012).

84. Granshaw, F. D. \& Fountain, A. G. Glacier change (1958-1998) in the North Cascades National Park Complex, Washington, USA. J. Glaciol. 52, 251-256 (2006).

85. Tad Pfeffer, W. et al. The Randolph Glacier Inventory: a globally complete inventory of glaciers. J. Glaciol. 60, 537-552 (2014).

86. Rastner, P. et al. The first complete inventory of the local glaciers and ice caps on Greenland. The Cryosphere 6, 1483-1495 (2012).

87. Bolch, T., Menounos, B. \& Wheate, R. Landsat-based inventory of glaciers in western Canada, 1985-2005. Remote Sens. Environ. 114, 127-137 (2010).

88. Pelto, B. M., Menounos, B. \& Marshall, S. J. Multi-year evaluation of airborne geodetic surveys to estimate seasonal mass balance, Columbia and Rocky Mountains, Canada. The Cryosphere 13, 1709-1727 (2019).

89. Wagnon, P. et al. Seasonal and annual mass balances of Mera and Pokalde glaciers (Nepal Himalaya) since 2007. The Cryosphere 7, 1769-1786 (2013).

90. Berthier, E., Schiefer, E., Clarke, G. K. C., Menounos, B. \& Rémy, F. Contribution of Alaskan glaciers to sea-level rise derived from satellite imagery. Nat. Geosci. 3, 92-95 (2010).

91. Berthier, E., Cabot, V., Vincent, C. \& Six, D. Decadal Region-Wide and Glacier-Wide Mass Balances Derived from Multi-Temporal ASTER Satellite Digital Elevation Models. Validation over the Mont-Blanc Area. Front Earth Sci. 4, 63 (2016).

92. Glacier Monitoring Switzerland. GLAMOS Swiss Glacier Volume Change, release 2018. (2018) doi:10.18750/volumechange.2018.r2018.

93. Bauder, A., Funk, M. \& Huss, M. Ice-volume changes of selected glaciers in the Swiss Alps since the end of the 19th century. Ann. Glaciol. 46, 145-149 (2007).

94. Davaze, L., Rabatel, A., Dufour, A., Hugonnet, R. \& Arnaud, Y. Region-Wide Annual Glacier 
Surface Mass Balance for the European Alps From 2000 to 2016. Front Earth Sci. 8, 149 (2020).

95. Schuler, T. V. et al. Reconciling Svalbard Glacier Mass Balance. Front Earth Sci. 8, 156 (2020).

96. Aðalgeirsdóttir, G. et al. Glacier Changes in Iceland From $\sim 1890$ to 2019. Front Earth Sci. 8, 520 (2020).

97. Hersbach, H. \& Dee, D. ERA5 reanalysis is in production. ECMWF newsletter 147, 5-6 (2016).

98. Skliris, N., Zika, J. D., Nurser, G., Josey, S. A. \& Marsh, R. Global water cycle amplifying at less than the Clausius-Clapeyron rate. Sci. Rep. 6, 38752 (2016).

99. Sakakibara, D., Sugiyama, S., Sawagaki, T., Marinsek, S. \& Skvarca, P. Rapid retreat, acceleration and thinning of Glaciar Upsala, Southern Patagonia Icefield, initiated in 2008. Ann. Glaciol. 54, 131-138 (2013).

100. Farr, T. G. et al. The Shuttle Radar Topography Mission. Rev. Geophys. 45, 1485 (2007).

\section{Data availability}

Global, regional, tile and per-glacier elevation and mass change time series, elevation change maps for 5-, 10- and 20-year periods at $100 \mathrm{~m}$ resolution, and tables of this article are publicly available at: https://doi.org/10.5281/zenodo.4530314.

\section{Code availability}

The code developed for the global processing and analysis of all data, and to generate figures and tables of this article is publicly available at https://github.com/rhugonnet/ww tvol_study. Code concomitantly developed for processing ASTER data is available as the python package pymmaster (v0.1) at https://pypi.org/project/pymmaster (with supporting documentation at https://mmaster-workflows.readthedocs.io) and for processing DEM time series as the python package pyddem (v0.1) at https://pypi.org/project/pyddem (with supporting documentation at https://pyddem.readthedocs.io).

\section{Acknowledgments}

We thank C. Porter for discussions on ArcticDEM and REMA DEMs, B. Meyssignac for comments on sea-level rise and A. Dehecq for input on the presentation of the manuscript. The GLIMS initiative (in particular J. Kargel and B. Raup) allowed the population of a vast archive of ASTER stereo images over glaciers. Hakai Institute and University of Northern British Columbia provided computational resources for processing ASTER stereo imagery. SPOT6/7 data were obtained thanks to GEOSUD (ANR-10-EQPX-20, program 'Investissements d'Avenir'). ArcticDEM DEMs were provided by the Polar Geospatial Center under NSF-OPP awards 1043681, 1559691, and 1542736 and REMA DEMs were 
provided by the Byrd Polar and Climate Research Center and the Polar Geospatial Center under NSF-OPP awards 1543501, 1810976, 1542736, 1559691, 1043681, 1541332, 0753663, 1548562, 1238993 and NASA award NNX10AN61G. Computer time provided through a Blue Waters Innovation Initiative. DEMs produced using data from DigitalGlobe, Inc. RH acknowledges a fellowship from the University of Toulouse. EB acknowledges support from the French Space Agency (CNES) through ISIS and TOSCA programs. RM, $\mathrm{CN}$, LG and AK acknowledge support by ESA through Glaciers_cci and EE10 (4000109873/14/I-NB， 4000127593/19/I-NS， 4000127656/19/NL/FF/gp), and by the European Research Council under the European Union's Seventh Framework Programme (FP/2007-2013) / ERC grant agreement no. 320816. BM acknowledges funding from the National Sciences and Engineering Research Council of Canada, the Canada Research Chairs Program and Global Water Futures. Authors with ETHZ affiliation acknowledge funding from the Swiss National Science Foundation, Grant Nr. 184634.

\section{Author contribution}

EB and RH designed the study with contributions from DF, MH and BM. LG, CN, RM and AK developed ASTER bias-correction methods. RH and RM developed glacier elevation Gaussian Process methods. RH implemented spatial statistics methods with inputs from FB. BM assembled and analyzed ERA5 data. RH performed the processing and analysis of all data with main inputs from EB, as well as RM, BM, DF, MH, ID and FB. All authors interpreted the results. RH led the writing of the paper and all other co-authors contributed.

\section{Competing interests}

The authors declare no competing interests.

\section{Additional information}

Supplementary information is available for this paper.

Correspondence and requests for materials should be addressed to RH.

Reprints and permissions information is available at www.nature.com/reprints.

\section{Extended Data}

\section{Extended Data Fig. 1. Flow chart of the methodology.}

Flow diagram describing the processing steps from satellite imagery to global glacier mass change time series. Processing steps correspond to sections of Methods.

\section{Extended Data Fig. 2. Spatial and temporal coverage of ASTER, ArcticDEM and REMA DEMs.}

Spatial distribution of DEMs as a strip count for ArcticDEM strips above 50 degrees North (a), ASTER DEM strips (b), and REMA strips below 50 degrees South (c), shown on top of a world hillshade $^{36}$. 67,986 ArcticDEM and 9,369 REMA strips are counted before co-registration to 
TanDEM-X. This later reduces their number to respectively 40,391 and 3,456 due to limited stable terrain in polar regions. d, Temporal distribution of the strip count as a bi-mensual histogram from January 2000 to December 2019. Note that ArcticDEM and REMA strip footprints ( $15 \mathrm{~km}$ by $50 \mathrm{~km}$ ) are generally much smaller than ASTER DEM strip footprints $(180 \mathrm{~km}$ by $60 \mathrm{~km})$.

\section{Extended Data Fig. 3. Elevation time series estimation.}

Empirical and modelled elevation measurement error (a) and temporal covariance of glacier elevation (b) estimated globally. Those are used to condition the filtering (c,d) and elevation time series estimation (e) of elevation observations, illustrated here for a $100 \mathrm{~m}$ by $100 \mathrm{~m}$ pixel on the ablation area of Upsala where a strong nonlinear elevation loss occurred ${ }^{99}$. a, Squared measurement error, estimated by the squared Normalized Median Absolute Deviation of elevation differences to TanDEM-X on stable terrain as a function of terrain slope and of quality of stereo-correlation. We express the quality of stereo-correlation as a percentage ranging from 0 for poor correlations to $100 \%$ for good correlations. b, Variance between pairwise glacier elevations in time, or temporal variogram. The empirical temporal variogram is derived from the aggregated median of variances binned by time lags of 0.25 year. Here, pixels were selected on glacierized terrain showing a linear trend of elevation change (estimated from weighted least squares) between -1.5 and $-1.0 \mathrm{~m}$ per year. The median of the linear trend at these locations (-1.2 m per year) was directly used to derive the linear model (orange) which has a quadratic variance. The other models are calibrated so that their sum (dashed black line) matches the empirical variogram. c, Spatial and temporal filtering by conditioning a maximum linear elevation change rate from the neighbouring TanDEM-X elevations (see Supplementary Information for further details). d, Filtering by successive Gaussian Process regression fits for credible intervals of size 20,12, 9, 6 and 4 standard deviations. e, Elevation time series of final Gaussian Process regression after the removal of outliers.

\section{Extended Data Fig. 4. Validation of elevation time series and uncertainties to ICESat and IceBridge.}

ICESat $^{64}$ and IceBridge ${ }^{65,66}$ measurements compared to our surface elevation time series over glacierized terrain in the Saint-Elias Mountains, Alaska (a-c), and at the global scale (d). b, Absolute Z-scores (white-to-purple) on top of 2000-2019 surface elevation change. Z-scores correspond to elevation differences to ICESat (dashed outlines) or IceBridge (solid outlines) standardized by our time series uncertainty. c, Time series for a $100 \mathrm{~m}$ by $100 \mathrm{~m}$ pixel extracted on the tongue of Agassiz Glacier with neighbouring ICESat and IceBridge elevation differences for demonstration purposes. d, Summary of global validation statistics for categories of time, seasons, region, elevation, observation time lag and total elevation change, with density distributions of measurements for ICESat (light grey) and IceBridge (dark grey). Mean elevation differences, subject to snow-cover biases, are shown only by region (summer mean) and by two-month seasonal component (difference to the annual mean) for each hemisphere.

\section{Extended Data Fig. 5. Uncertainty analysis and validation to high-resolution DEMs.}

Spatial correlation of elevations between the Gaussian Process (GP) time series and ICESat with the time lag to the closest ASTER, ArcticDEM or REMA observation (a,b), propagation of correlations into specific volume change uncertainties (c), validation of volume change estimates and uncertainties to high-resolution volume changes extracted over the same 588 glaciers and periods (d-f) and contribution from all uncertainty sources to the 2000-2019 specific mass change estimates (g,h). a, 
Empirical spatial variogram is shown and fitted with a sum of spherical models at correlation length of $0.1,2,5,20,50,200$ and $500 \mathrm{~km}$ for elevation differences sampled at 720 days (2 years) from the closest observation. b, Spatially correlated variances as a function of the time lag to the closest observation. The model used for the variance used during error propagation is shown in plain lines (sum of quadratic and squared sinusoidal functions optimized by least squares). c, Propagation of elevation change uncertainties to volume change uncertainties with varying glacier area. As this computation is specific to the time lag of each pixel to the closest observation, for each glacier, at each time step, panel (c) refers to an example. The spatial correlations are computed for a time lag to the closest observation, representing the average of our study, of $0-1$ year for $50 \%$ of observations, 1-2-years for $20 \%$ of observations, 2-3 years for $20 \%$ of observations and 3-4 years for $10 \%$ of observations. We assume a mean pixel-wise error of $10 \mathrm{~m}$ and simplify by considering only the first step of integration over a continuous glacierized area (Equation 5). This assumption leads to slightly larger contributions from short-range correlations than with further propagation to the second propagation step between discontinuous glaciers (Equation 6). Uncertainties are largely dominated by short- to long-range spatial correlations. d, Comparison of specific volume changes per glacier with 1 -sigma uncertainties. The mean of differences in estimates over all glaciers does not statistically differ from zero. e,f, Theoretical and empirical uncertainties, and their evolution with glacier size. The theoretical uncertainty is the mean of glacier errors derived from spatially integrated variograms and the empirical uncertainty is the Normalized Median Absolute Difference of the difference between high-resolution and GP estimates. $\mathbf{g}, \mathbf{h}$, Propagation of uncertainty sources to specific mass changes for each RGI region, and all glaciers with and without the Greenland Periphery and the Antarctic and Subantarctic which are zoomed on panel (h). Uncertainties are largely dominated by the volume-to-mass conversion uncertainties globally, and by uncertainties in glacier outlines for regions with a relevant share of small glaciers.

\section{Extended Data Fig. 6. Two decades of elevation change over various regions.}

Elevation change of glaciers between 2000 and 2019 in Coropuna, Peru (a), the Pamir Mountains (b), Iceland (c), the Karakoram Mountains (d), the European Alps (e), the Southern Alps, New Zealand (f) , West Greenland (note rotated orientation of map) (g), and Svalbard (h). Except for Svalbard, glacier outlines displayed are from the RGI6.0. In the background is shown a hillshade derived from several sources $^{36,46,100}$. In Svalbard, outlines have been updated to include the massive surges of Austfonna basin $3^{38,39}$ in the northeast and Nathorstbreen in the southwest ${ }^{40}$, indicated by blue arrows.

\section{Extended Data Fig. 7. Global evolution of 5-year thinning rates.}

Mean elevation change rates aggregated by tiles of $1^{\circ} \times 1^{\circ}$ for the periods 2000-2004 (a), 2005-2009 (b), 2010-2014 (c) and 2015-2019 (d). Tile area is inversely scaled to the squared 95\% CI of the mean elevation change in the tile and tiles are colored with mean elevation change rates, on top of a world hillshade ${ }^{36}$. Minimum tile area is $10 \%$ for $95 \%$ CI larger than $2 \mathrm{~m} \mathrm{yr}^{-1}$ and tiles are displayed at full size for $95 \%$ CI smaller than $0.5 \mathrm{~m} \mathrm{yr}^{-1}$. Region labeling refers to that of Fig. 2. The acceleration of thinning brings the Karakoram anomaly to its apparent end.

\section{Extended Data Table 1. Regional rates of glacier elevation and mass change from 2000 to 2019.}

Regional and global mean elevation change and mass change rates over full and 5-year periods of 2000-2019. Mean elevation change is the volume change divided by time-evolving regional glacier areas (see Methods) ${ }^{21}$. Areas reported are those of the RGI 6.0 inventory ${ }^{22}$, except for region 12 
(Caucasus Middle East) which was updated with more recent outlines ${ }^{37}$. Periods are inclusive and refer to calendar years of 1 st January to 31 st December. Uncertainties correspond to $95 \%$ confidence intervals. In Greenland, glaciers highly connected to the ice sheet (RGI connectivity level 2) are not reported.

\section{Extended Data Table 2. Regional data coverage of elevation time series from 2000 to} 2019.

Spatial and temporal coverage of our elevation time series after the three steps of elevation outlier filtering. Nominal glaciers correspond to uncharted glaciers inventoried in the RGI with only an estimated surface area, present notably in region 10 (North Asia) where they contribute to $3.0 \%$ of the region total glacier area. Those are accounted for in our volume change estimates by applying the mean elevation change of the region to their reported area. Glaciers without any coverage correspond to glaciers having no valid, post-filtering elevation change observation within their outline. This generally occurs when repeat spatial sampling is poor (less than 3 observations in 20 years) for small glaciers located in high slopes.

Extended Data Table 3. Regional rates of land- and marine-terminating glaciers in maritime regions.

Uncertainties correspond to $95 \%$ confidence intervals. For marine-terminating glaciers, subaqueous losses are not included (see Methods). 